\title{
6 Ausblick
}

Alle drei Neuentwicklungen präzisieren die Performancemessung ökonomischen Eigenkapitals. Die Performancemessung wird hierdurch hinsichtlich der finanziellen Dimensionen korrigiert, das ökonomische Eigenkapital ist noch effizienter einsetzbar, und die Geschäftssteuerung einer Bank kann sich wie in einem kybernetischen Regelkreislauf selbst steuern.

Der für alle Neuentwicklungen neue methodische Schritt ist die Darstellung des ökonomischen Eigenkapitals als Flußgröße. Diese Eigenkapitalflußfunktion wird aus der Eigenkapitalbestandsfunktion nicht durch Differentiation, sondern lediglich eine Differenzenbildung gebildet.

Der Umstand der Differenzenbildung scheint darauf hinzudeuten, da $\beta$ stetige Berechnungen wie zum Beispiel eine stetige Verzinsung oder die Optionspreisermittlung auf Basis stetiger Wahrscheinlichkeitsfunktionen lediglich eine Näherung darstellen: Die Welt der Finanzmärkte scheint genauso wie die der Atomphysik nach dem derzeitigen Wissensstand gequantelt, also diskret zu sein. Außerdem ist erstaunlich, daß wie bei den meisten kleine, aber auch komplexen Problemstellungen, die mathematisch gelöst werden, das Ergebnis sehr häufig durch einen kurzen, prägnanten Term ausgedrückt wird und vom Augenschein die dahinterliegende Komplexität verdeckt.

Alle drei Neuentwicklungen sowie die Vermutung, daß die Welt der Finanzmärkte diskret zu sein scheinen, warten darauf, verworfen, bestätigt beziehungsweise weiterentwickelt zu werden. 